\title{
Propuesta
}

\section{Experiencias en Comunicación Alternativa Enfocadas a la Construcción de paZ con una Mirada de Género en Santiago de Cali (2008-2012)}

\author{
Por: Derly Johana Moreno Flechas \\ Comunicadora Social y Periodista - Corporación Universitaria del Meta \\ Maestrante en Derechos Humanos y Cultura de Paz - \\ Pontificia Universidad Javeriana de Cali
}

El tema propuesto para la investigación aplicada a la Maestría en Derechos Humanos y Cultura de Paz de la Pontificia Javeriana de Cali, articula perfectamente en el ámbito conceptual de los Derechos Humanos, la Construcción de Paz y Cultura de Paz con el grupo de investigación adscrito a la Universidad - Pensar en Clave de Género, dirigido por la Dra. María Irene Victoria. El enfoque diferencial y de Género, la Comunicación Alternativa y la Cultura de Paz se constituyen en los pilares fundamentales de mi propuesta para describir, evaluar y analizar las acciones de intervención social realizadas desde la sociedad civil enfocadas directamente a la construcción de paz no solo en Santiago de Cali sino en el país.

Basada en mi experiencia académica, profesional y laboral en Comunicación para el desarrollo social, la formación y el acompañamiento a diferentes comunidades en la implementación y acompañamiento en proyectos de Comunicación Alternativa, convierte esta propuesta de investigación una oportunidad de incluir en el grupo de investigación- Pensar en Clave de Género, el tema de la Comunicación para el desarrollo social como un agente generador de conocimiento al Valle del Cauca.

Dicha investigación se realiza con el fin de describir, evaluar y analizar las acciones basadas en las experiencias de Comunicación Alternativa para la construcción de paz que realizan las organizaciones de mujeres víctimas del conflicto armado y violencia sexual en la ciudad de Santiago de Cali. Se tomará como casos particulares los ejercicios locales como: primero, el realizado por la Confluencia Departamental de Organizaciones de Mujeres Valle del Cauca, cuya propuesta consiste en: a. Fortalecer la capacidad de las mujeres organizadas para representar sus propios intereses, formular propuestas e incidir en los espacios de toma de decisiones en los municipios y en el departamento; b. Mejorar la habilidad de las mujeres para la interlocución con otras mujeres, con otros sectores sociales y con las instituciones públicas; c. Construir y compartir nuevas lógicas y lenguajes comunes, maneras novedosas de incursionar en el mundo público, de renovar las prácticas políticas y re-crear las relaciones de poder en los ámbitos privados y públicos, hacia mayores niveles de equidad y democracia y; d. Acompañar los procesos de cambio y empoderamiento, personales y colectivos, de las mujeres del departamento reconociendo la diversidad y la exclusión social, política y cultural.

Segundo, el realizado por la Corporación Centro de Acciones para la Mujer (CAMI) que tiene como propuesta: a. El desarrollo social a través del fortalecimiento de la equidad social y de género, el posicionamiento de las mujeres en la sociedad y el desarrollo de procesos democráticos fundamentados en la construcción de sujetos de derechos sociales y políticos; b. Formación de voceras en temas de agenda de género; c. Incidencia política y movilización; d. Comunicación y difusión; e. Generación de nuevos conocimientos para la intervención social. Y por último, el trabajo que viene realizando Taller Abierto en relación a : a. Promover el fortalecimiento y la transformación de identidades y relaciones para la equidad social, de género, interculturalidad y convivencia pacífica; b. Desarrollar programas y proyectos que aporten al mejoramiento de la calidad de vida de las comunidades; c. Fomentar la promoción y defensa de los derechos humanos y; d. Contribuir a la construcción y consolidación de movimientos sociales de mujeres, jóvenes y niñez, entre otras. 


\section{ISSN-2248-736 * Número 3 * Revista Facta Non Verba}

Dichas iniciativas en su quehacer institucional han permitido hacer visible los Derechos de las Mujeres a través de los medios de comunicación de mayor impacto social como son: la radio, la prensa, el internet y la televisión, convirtiéndose en uno de los pilares fundamentales para el intercambio del conocimiento, la opinión, la información y la incidencia en la agenda pública.

En este contexto se crea la necesidad de analizar las experiencias de intervención social que encuentran a través de la comunicación y las diferentes herramientas comunicativas, el desarrollo capacidades de empoderamiento y promoción de una cultura de paz desde el trabajo organizativo de las mujeres en Santiago de Cali. En la actualidad no existe un análisis sobre la importancia y el papel fundamental que juegan dichas acciones en la construcción de alternativas de paz. Resulta pertinente evaluar si dicho ejercicio ha contribuido o no en la generación de impactos significativos no solo en su entorno comunitario sino en la ciudad.

Por lo tanto se plantea la siguiente pregunta como eje transversal en la investigación: ¿Cómo los ejercicios de comunicación alternativa desarrollados por las organizaciones de mujeres en Santiago de Cali han generado elementos para la construcción de paz y si éstos han impactado en aspectos políticos y sociales?

E1 enfoque diferencial y de género, la comunicación alternativa y la cultura de paz se constituyen en los pilares fundamentales de esta propuesta de investigación; por tal motivo para poder evaluar los impactos políticos y sociales que tienen los ejercicios de comunicación alternativa en la construcción de paz, haré referencia a dos enfoques teóricos: La comunicación alternativa y la Cultura de paz.

Entendiéndose la Comunicación Alternativa como un modelo de comunicación que se ha venido manifestando desde la Segunda Guerra Mundial en los países denominados tercermundistas donde las problemáticas sociales, políticas y culturales comienzan a tomar un valor significativo en sus comunidades, y cuyo fin es poder conquistar espacios de comunicación en los sectores de la sociedad que se encuentran reprimidos o que están socialmente estancados y marginados de la participación política y que no han tenido la posibilidad de acceder a los medios de comunicación del Estado o de la empresa privada; por todo ello surge la comunicación alternativa.
Estos diferentes grupos sociales se aglutinan por sus ideologías, sus necesidades comunes y por su necesidad de encontrar un espacio de expresión. Por eso el aspecto fundamental de este modelo es la apropiación de los medios, que debe entenderse como un modo de desarrollar la capacidad propia, comunitaria y colectiva, y de adoptar la comunicación y sus medios como un proceso coadyuvante de las luchas sociales. (Gumucio-Dagrón, 2009).

En referencia al concepto de Cultura de Paz ha sido promovido y proclamado por la Asamblea General de las Naciones Unidas de la siguiente manera: Consiste en valores, actitudes y conductas que plasman y suscitan a la vez interacciones e intercambios sociales basados en principios de libertad, justicia y democracia, todos los derechos humanos, la tolerancia y la solidaridad, que rechazan la violencia y procuran prevenir los conflictos tratando de atacar sus causas para solucionar los problemas mediante el diálogo y la negociación y que garantizan el pleno ejercicio de todos los derechos y proporcionan los medios para participar plenamente en el proceso de desarrollo de su sociedad. (1998, Resolución A/5213).

Cabe resaltar en el ámbito internacional las iniciativas para la construcción de paz realizadas por la oficina de la Organización de las Naciones Unidas para la Educación, la Ciencia y la Cultura (UNESCO) en México con el programa Conjunto referente a la reducción de la conflictividad mediante la construcción de una cultura de paz y la recomposición del tejido social a través de la educación para la paz, la educación artística y la comunicación al desarrollo. En lo referente a la comunicación para el desarrollo, ésta iniciativa logró capacitar por lo menos unas 70 personas como "Comunicadores comunitarios" haciéndolos participantes a la red de voceros de las realidades y necesidades de sus comunidades promoviendo la paz mediante la utilización de herramientas de comunicación alternativa en radio, prensa y producción audiovisual.

Considerando entonces dichas iniciativas internacionales y locales como punto de partida para la construcción de una cultura de paz en las naciones como poderosos instrumentos para la promoción del diálogo, generación de acuerdos y la construcción de la paz, es relevante de igual forma analizarlos, sistematizarlos y evaluarlos de tal forma comprender su impacto en la sociedad.

\section{Metodología de la investigación}

La población objeto de la investigación son los diferentes 
actores clave como:

académicos, directores de medios de comunicación, funcionarios públicos, las organizaciones de mujeres de todas las edades y etnias del sector urbano marginal, organizaciones de mujeres comunitarias y mixtas cuyos propósitos para la movilización social sea la promoción y defensa de los Derechos Humanos, la Educación para la Paz y la Construcción de Paz y; que además encuentren en las diferentes herramientas de comunicación alternativa (Radio, prensa, internet y televisión) una opción para el desarrollo de capacidades de empoderamiento y promoción de una cultura de paz en la ciudad. Información primaria: ésta consiste en la recolección directa de la información a través de instrumentos de recolección de información que pueden ser: testimonios, observaciones y entrevistas a los actores clave plenamente identificados. Los instrumentos a utilizar para la recolección primaria son: grupo focal, recolección de testimonios, entrevistas estructuradas y la observación no estructurada.

Información secundaria: esta consiste en la recolección de información mediante el contacto indirecto con la población objeto de estudio. Para esto la técnica a utilizar para el registro de información secundaria es la ficha de contenido. Esta técnica es de carácter documental (prensa, archivos o libros) registra y consigna extractos o aportes completos, citas textuales y resúmenes de libros, ensayos, artículos y periódicos.

Así como está planteado en los objetivos específicos, luego de identificar las organizaciones de mujeres que han diseñado e implementado ejercicios de comunicación alternativa, es importante sistematizar los que hayan tenido mayor impacto en la comunidad y en la ciudad de Santiago de Cali.

Partiendo de la sistematización de experiencias de desarrollo con énfasis en los procesos y las estrategias de intervención entre los propósitos se encuentra recuperar, reconstruir, organizar y procesar dichas experiencias para interpretar críticamente los hechos y así obtener de ellas aprendizajes y lecciones que permitan mejorar las prácticas promovidas por la sociedad civil y organizaciones sociales de la ciudad.

Llevar dicha propuesta de investigación al análisis y evaluación de los impactos políticos, sociales que tienen los ejercicios de comunicación alternativa para la construcción de paz en nuestro país, representaría una oportunidad de crecimiento personal, académico y profesional.

\section{FUENTES}

\section{Bibliografía:}

- Terrero, Martínez José. (2006). Teorías de Comunicación. Ciudad Guayana, Venezuela.

- Lugo López, Cristóbal (2011). La Sistematización de las Prácticas Sociales "Un proceso de reflexión y empoderamiento de lo que hacemos". Observatorio del Territorio de la Universidad de los Llanos, Villavicencio, Meta, Colombia.

Documentos oficiales

- Resolución aprobada por la Asamblea General de las Naciones Unidas 52/13. (1998, Enero).

- Resolución aprobada por la Asamblea General de las Naciones Unidas 52/15. (1998, Enero).

Documentos en internet

- Elizabeth McCall (2011). Comunicación para el Desarrollo - Fortaleciendo la Eficacia de las Naciones Unidas. - Frances J Berrigan. (1981). La Comunicación Comunitaria- Cometido de los medios de comunicación comunitaria en el desarrollo. Paris, France. Editorial de laUnesco. -DelCastilloMontero,LinaMaría.(2009).Comunicación Alternativa y Comunitaria: Aproximaciones a dos experiencias juveniles en Bogotá. Trabajo de grado publicado. Pontificia Universidad Javeriana, Bogotá, Colombia.

Seminarios y Diplomado

- Universidad del Rosario. Diplomado en Género y

Justicia Transicional, Villavicencio, Abril -2012.

\section{Referencias electrónicas/ Páginas web oficiales}

- http://www.fao.org/index_es.htm

- http://www.unesco.org/new/es/unesco/ 